Special issue of the 3rd International Conference on Computational and Experimental Science and Engineering (ICCESEN 2016)

\title{
Effect of Layer Thickness on $I-V$ Characteristics of GaInP Nanofibers Fabricated by Electrospinning on $\boldsymbol{n}$-Si Substrates
}

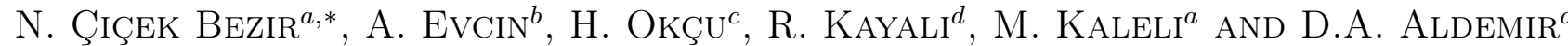 \\ ${ }^{a}$ Department of Physics, Faculty of Art and Science, Suleyman Demirel University, 32260 Isparta, Turkey \\ ${ }^{b}$ Department of Materials Science and Engineering, Faculty of Engineering, Afyon Kocatepe University, \\ 03200 Afyonkarahisar, Turkey \\ ${ }^{c}$ Graduate School of Natural and Applied Sciences, Suleyman Demirel University, 32260 Isparta, Turkey \\ ${ }^{d}$ Department of Physics, Faculty of Art and Science, Ömer Halisdemir University, 51200 Nigde, Turkey \\ GaInP nanofibers were formed on $n$-Si substrates by electrospinning method, using constant voltage $(25 \mathrm{kV})$, \\ height $(6 \mathrm{~cm})$, and flow rate $(0.3 \mathrm{ml} / \mathrm{h})$ during various process times (of 10, 20,25 minutes). Characterization of \\ the prepared samples was performed by X-ray diffraction, differential scanning calorimetry/thermal gravimetric \\ analysis, scanning electron microscopy, and energy dispersive X-ray spectrometry. Furthermore, the current- \\ voltage measurements of the $\mathrm{GaInP} / n$-Si samples have been carried out. The obtained results show that $I-V$ \\ characteristics of all $\mathrm{GaInP} / n$-Si samples fabricated with three thicknesses of GaInP layers are rather in a good \\ agreement with the theory and that they exhibit rectifying properties.
}

DOI: 10.12693/APhysPolA.132.638

PACS/topics: 81.07.-b, 73.61.Le, 81.07.Gf

\section{Introduction}

Electrospinning technique has received a great attention due to its low cost and ability to produce nanofibers with diameters ranging from a few microns to nanometers and due to their large surface area to volume ratio [1-4]. Electronic, optical, electrical, and mechanical properties of such fibers can be easily modified $[5,6]$. Thus, nanofibers fabricated by electrospinning technique, have attracted considerable interest, to be used in many important applications, such as various sensors, solar cells, and photocatalytic devices [5-13].

The ternary GaInP alloys are used very often for the fabrication of the tandem solar cells, lasers, LEDs and HEMTs, since their lattice matches that of GaAs. On the other hand, these alloys have a rather large, direct band gap of $1.88 \mathrm{eV}$. Because of this, they exhibit some merits due to the defect centers, which cause a decrease of the conductivity $[10,14,15]$. GaInP/Si junctions are good candidates for tunneling junctions in multijunction cells and LEDs [10-16].

In this study, we investigate the morphological and structural properties of GaInP nanofibers deposited on $n$-Si, with three different thicknesses, by using electrospinning technique. Furthermore, we have conducted the current-voltage $(I-V)$ measurements and discuss the electrical properties of $\mathrm{InGaP} / n$-Si hetero junction diode.

\section{Experimental}

In this study, we have prepared a solution of $\mathrm{Ga}_{0.50} \operatorname{In}_{0.50} \mathrm{P}$ using three different materials: $11.48 \mathrm{~g}$

*corresponding author; e-mail: cicekn@gmail.com of trimethylgallium (TMGa) and $15.99 \mathrm{~g}$ of trimethylindium (TMIn), in the form of gas and $18 \mathrm{~g}$ of tertiarybutylphosphine (TBP) in the form of liquid.

First, we put $15.99 \mathrm{~g}$ of trimethylindium (TMIn) into the distillation flask and then we injected the other two gas materials into this flask and closed the inlets. Then, we mixed these materials by stirring with a magnetic mixer for $0.5 \mathrm{~h}$ to obtain a homogeneous solution. We took then $10 \mathrm{ml}$ of the solution and put it in a beaker. After this, we dissolved $1 \mathrm{~g}$ of PVP in $10 \mathrm{ml}$ of ethanol. Then, we poured $10 \mathrm{ml}$ of the first solution in the solution prepared with PVP, mixed them vigorously using magnetic mixer at room temperature for $10 \mathrm{minu}-$ tes and obtained the solution that was used to fabricate the $\mathrm{Ga}_{0.50} \mathrm{In}_{0.50} \mathrm{P}$ nanofibers.

The electrospinning apparatus used in this experiment consists of a plastic syringe, equipped with a needle (22 gauge), a syringe pump (Top Syringe Pump Top-5300), a high voltage power supply (Gamma High Voltage ES30) and a grounded collector (aluminium foil and $n$-type silicon wafers with resistivity value of $1-10 \Omega \mathrm{cm})$. The needle was connected to a high-voltage supply and the solution was fed at a constant rate of $0.3 \mathrm{ml} / \mathrm{h}$, using the syringe pump.

$n$-Si substrate was placed on a grounded collector $6 \mathrm{~cm}$ below the tip of the needle (Fig. 1) to collect the produced nanofibers. Then, the nanofibers were fabricated by applying an electric field of $25 \mathrm{kV}$ and finally, the obtained nanofibers were annealed at $500^{\circ} \mathrm{C}$.

The morphology and average fiber diameters of produced GaInP nanofibers were observed under SEM (Leo $1430 \mathrm{VP})$. XRD measurements were performed for crystal phase identification of the samples, using XRD (Bruker D8 Advance) with $\mathrm{Cu} \mathrm{K}_{\alpha}$ radiation $(\lambda=$ $1.5418 \AA$ ) at $40 \mathrm{kV}$ and $40 \mathrm{~mA}$. The thermal properties 


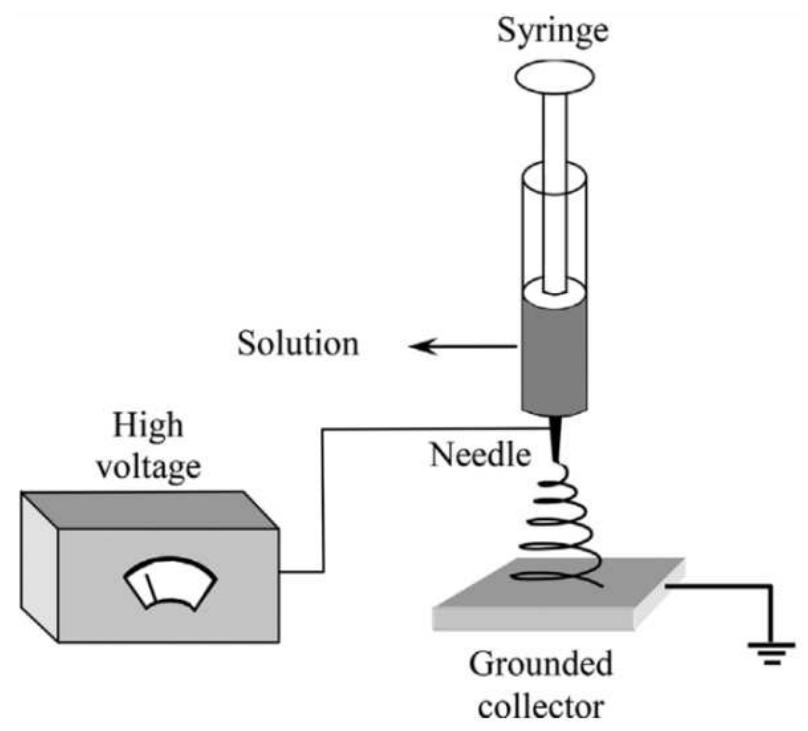

Fig. 1. Electrospinning set-up [3].

of the electrospun GaInP nanofibers were characterized by TG-DSC (Netzsch STA449F3) at a heating rate of $20^{\circ} \mathrm{C} / \mathrm{min}$ in $\mathrm{N}_{2}$ atmosphere. Current-voltage $(I-V)$ measurements were carried out using Keithley 2400 source meter in darkness.

\section{Results and discussion}

It is vital to know at which temperatures the crystallization of GaInP nanofibers and the removal of PVP and volatile solvents start. For this purpose, DSC/TG analysis was used to identify the optimal initial temperature for the calcination process. The thermal behavior of mixture as-electrospun GaInP/PVP is shown in Fig. 2. The TG curves show two distinct stages of weight loss. As seen from Fig. 2, the DSC curve shows that an endothermic reaction peak at $95^{\circ} \mathrm{C}$ occurs due to the removal of residual water in the structure [17]. As can be seen from the TG curve in Fig. 2, the water retention has caused about $20 \%$ of weight loss.

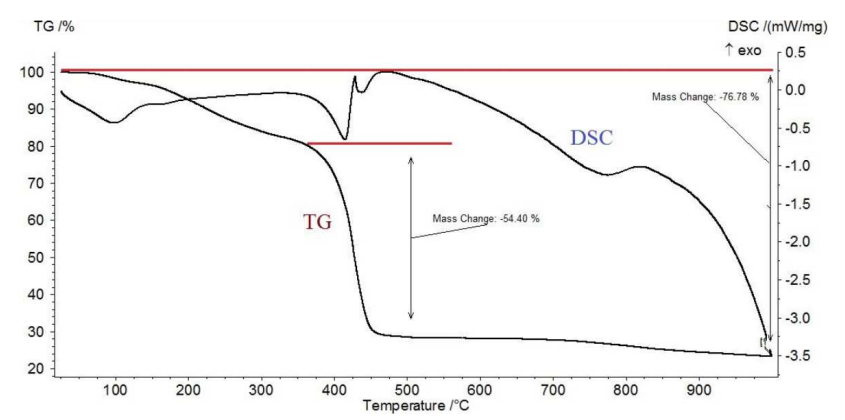

Fig. 2. DTA/TGA analysis of GaInP nanofibers.

Thermal decomposition of the PVP begins at temperatures higher than $300^{\circ} \mathrm{C}$ in air, under atmospheric pressure, and during this time interval all PVP is removed.
This shows that an exothermic reaction occurs at this temperature, in accordance with literature. The removal of PVP corresponds to a weight loss of about $54 \%$, as shown in the TG curve (Fig. 2) [7,17,18].

Above $450^{\circ} \mathrm{C}$, no distinctive weight loss was observed. This shows that an exothermic reaction occurs at this temperature $\left(450^{\circ} \mathrm{C}\right)$, in accordance with literature $[17,18]$. The second top point appears at $500^{\circ} \mathrm{C}$, showing the second exothermic reaction, indicating that there is a reaction between gallium, indium and phosphorus [19]. As seen from Fig. 2, TG curve shows weight losses of the sample with temperature and confirms the results obtained from DSC measurement. As seen from Fig. 2, the weight loss is in the range of more than $75 \%$. Heat treatment temperature was chosen as $500^{\circ} \mathrm{C}$, which corresponds to the end of the exothermic reaction.

SEM images of the GaInP nanofibers formed on $n$-Si substrates at different process times $(10,20$, and $25 \mathrm{mi}-$ nutes) are given in Fig. 3a-c, respectively. As can be seen from Fig. $3 \mathrm{a}-\mathrm{c}$, the homogeneity of the fiber diameters increases with increasing process time, as the bead formation and diameters decrease with increasing process time.

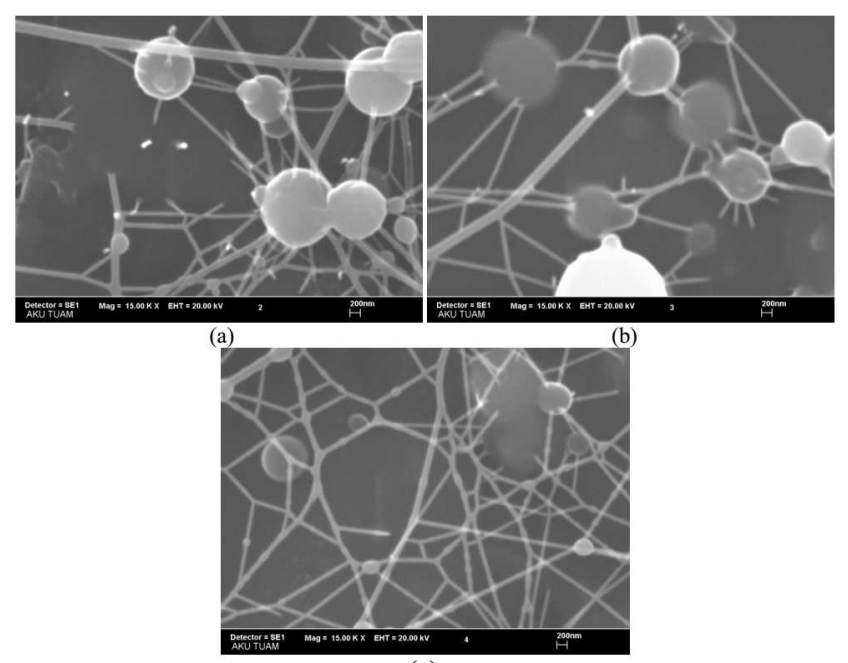

(c)

Fig. 3. SEM images of GaInP nanofibers processed for (a) 10, (b) 20 and (c) 25 minutes on $n$-Si substrates.

The presence of Ga, In, and P in the fibers is confirmed in Fig. 4 by elemental mapping, obtained using energy dispersive X-ray (EDX) analysis. Figure 4 shows EDX analysis of GaInP nanofibers. Chemical composition of the fabricated nanofibers is reliable. Carbon and oxygen elements originate from polymer solvents and aluminum signal originates from the aluminum collector plate.

Figure 5 shows the XRD patterns of pure GaInP (black), of gallium indium oxide (red), indium oxide (blue) and gallium phosphate (green), which suggest that our film is polycrystalline. The results are in a good agreement with literature [20-22].

The current-voltage $(I-V)$ measurements of the $\mathrm{GaInP} / n$-Si heterostructures were conducted at room 


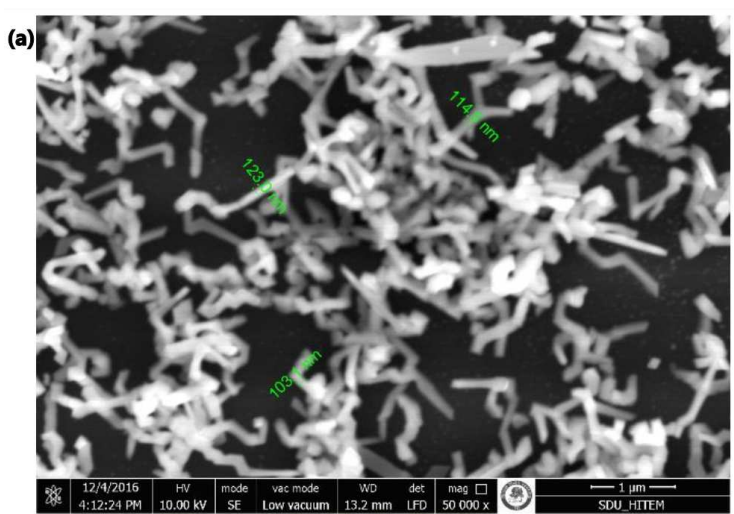

(b)

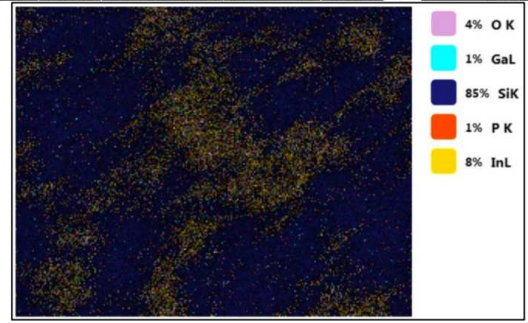

(c)

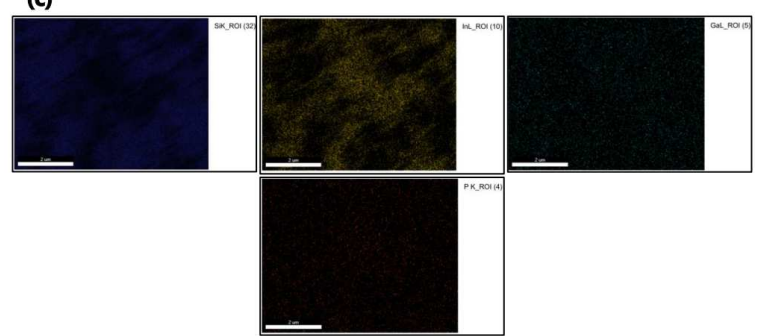

Fig. 4. EDX mapping analysis of GaInP nanofibers on $n$-Si wafer; (a) topographical image of GaInP nanofibers, (b) overall mapping image of $\mathrm{Ga}$, In and $\mathrm{P}$ elements on Si wafer, (c) separated mapping of each elements ( $\mathrm{Si}, \mathrm{In}, \mathrm{Ga}$ and $\mathrm{P}$ ).

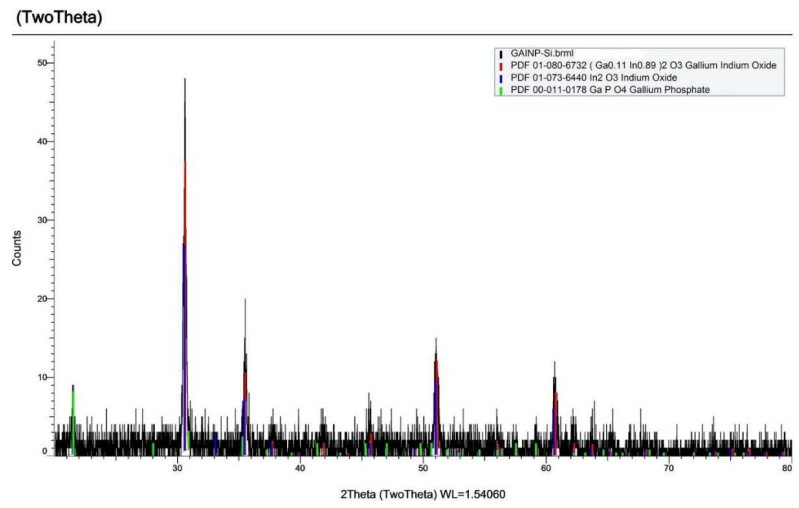

Fig. 5. XRD pattern of GaInP nanofibers on $n$-Si substrate heated at $500{ }^{\circ} \mathrm{C}$.

temperature using contacts made with $\mathrm{Ag}$ paste. Figure 6 shows $I-V$ characteristics of $\mathrm{GaInP} / n$-Si heterostructures for various times of deposition of the nanofibers on the substrates. The labels of GaInP10, GaInP20, GaInP25 represent the nanofiber films deposited for 10, 20 and 25 minutes, respectively. The label
"Ref." represents $\mathrm{Ag}$ paste on $n$-Si without $\mathrm{GaInP}$ nanofiber film. As can be seen in Fig. 6, GaInP $/ n$-Si heterostructures exhibit rectifying behavior and the threshold voltage changes depending on the deposition time. As the deposition time increases, the thickness of GaInP nanofiber films on $n$-Si increases and GaInP transforms from thin-film into the bulk structure. Thus the threshold voltage of $\mathrm{GaInP} / n$-Si heterostructures decreases with increasing deposition time.

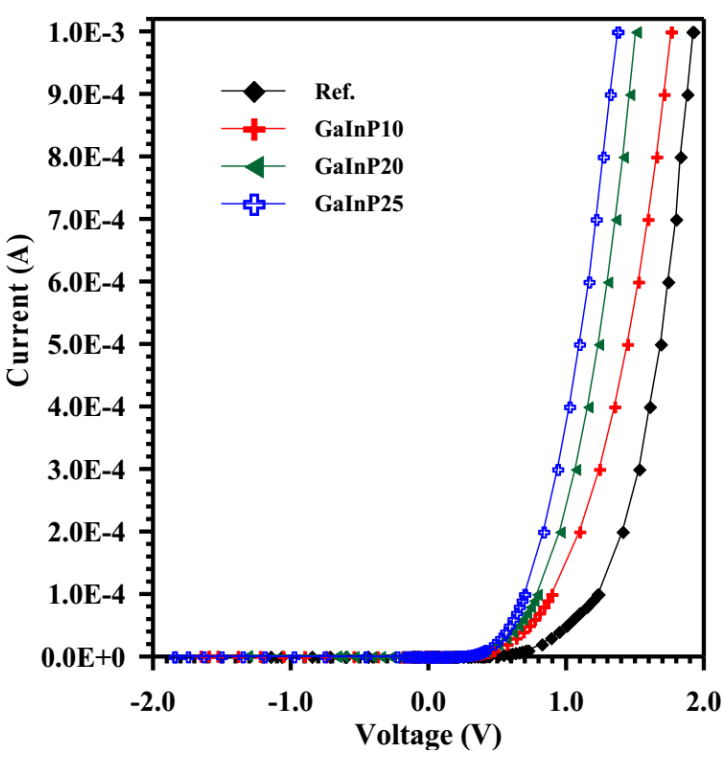

Fig. 6. The $I-V$ characteristics of the $\mathrm{GaInP} / n-\mathrm{Si}$ heterostructures at room temperature.

\section{Conclusions}

GaInP nanofibers were deposited on Si substrates by electrospinning method and the samples were annealed at $500^{\circ} \mathrm{C}$. The morphology, structural, surface and electrical properties of nanofibers were studied and the following results were obtained:

- While the morphologies of the nanofibers for the process times of 10 and 20 minutes are similar, the nanofibers produced during the process time of 25 minutes have become more homogeneous and less beaded. The increase in the process time causes a decrease in the nanopore diameters.

- Chemical compositions of the samples determined by XRD are as expected.

- $I-V$ measurements have shown that there is a change in the electrical properties of the structures with the increasing thickness of the nanofiber layer, formed on the substrates. This result shows that the traps depths become smaller. This means that photons of solar spectrum, with smaller energies, are also going to produce free electrons. Thus, this result is very important for the research of photovoltaic cells. 


\section{Acknowledgments}

We are very grateful to Turkish Scientific and Technologic Research Council [TUBITAK PROJECT-110M344] and Süleyman Demirel University Research Projects Coordination Unit (No: 3811-YL1-13).

\section{References}

[1] F.A. Sheikh, N.A.M. Barakat, M.A. Kanjwal, S.J. Park, H. Kim, H.Y. Kim, Fibers Polym. 11, $384(2010)$.

[2] S.T. Aruna, L.S. Balaji, S. Senthil Kumar, B. Shri Prakash, Renew. Sustainable Energy Rev. 67, 673 (2017).

[3] C. Ayranci, J.P. Carey, Electrospinning for braiding, Handbook of Advances in Braided Composite Materials, 2017, p. 419 .

[4] O. Karatay, M. Doğan, Appl. Nanobiomater. 2, 359 (2016).

[5] A.F. Lotus, S. Bhargava, E.T. Bender, E.A. Evans, R.D. Ramsier, D.H. Reneker, G.G. Chase, J. Appl. Phys. 106, 14303 (2009).

[6] J. He, Acta Phys. Pol. A 121, 254 (2012).

[7] A. Evcin, N.C. Bezir, R. Kayali, M. Ari, D.B. Kepekci, Crystal Res. Technol. 49, 303 (2014).

[8] K. Fujihara, A. Kumar, R. Jose, S. Ramakrishna, S. Uchida, Nanotechnol. 18, 365709 (2007).

[9] M. Li, G. Han, B. Yang, Electrochem. Communicat. 10, $880(2008)$
[10] C.C. Hu, C.S. Sheu, M.K. Lee, Mater. Chem. Phys. 48, 17 (1997)

[11] U. Bunyatova, Z. Rzayev, İ. Koçum, M. Şimşek, M. Yürüksoy, Acta Phys. Pol. A 129, 431 (2016).

[12] N. Çiçek Bezir, A. Evcin, R. Kayali, M. Kasikçi Özen, K. Esen, E.B. Cambaz, Acta Phys. Pol. A 130, 300 (2016).

[13] A. Evcin, N. Çiçek Bezir, R. Kayalı, M. Kaşıkcı Özen, A. Oktay, Acta Phys. Pol. A 128, B-303 (2015).

[14] O. Martínez, V. Hortelano, V. Parra, J. Jimenez, T. Prutskij, C. Pelosi, MRS Proceedings 1167, O0304 (2009)

[15] A. Kozanecki, Acta Phys. Pol. A 90, 73 (1996).

[16] J. Liang, M. Morimoto, S. Nishida, N. Shigekawa, Phys. Status Solidi C 10, 1644 (2013).

[17] W. Feng, H. Tao, Y. Liu, Y. Liu, J. Mater. Sci. Technol. Shenyang 22, 230 (2006).

[18] Y.K. Du, P. Yang, Z.G. Mou, N.P. Hua, L. Jiang, J. Appl. Polym. Sci. 99, 23 (2006).

[19] Z. Liu, Y. Bai, D. Cui, Q. Wang, Solid State Sci. 5 , 1037 (2003)

[20] C.E. Knapp, G. Hyett, I.P. Parkin, C.J. Carmalt, Chem. Mater. 23, 1719 (2011).

[21] O.M Berengue, A.D. Rodrigues, C.J. Dalmaschio, A.J.C. Lanfredi, E.R. Leite, A.J. Chiquito, J. Phys. D: Appl. Phys. 43, 045401 (2010).

[22] H.W. Seo, S.Y. Bae, J. Park, H. Yang, S. Kim, Chem. Commun. 21, 2564 (2002) 